\title{
Community participation and maternal health service utilization: lessons from the health extension programme in rural southern Ethiopia
}

\author{
Daniel G Datiko1, Elias M Bunte', Gemeda B Birrie', Aschenak Z Kea1', Rosie Steege², M Taegtmeyer², \\ Meghan Bruce Kumar', Maryse C Kok ${ }^{3}$ \\ ${ }^{1}$ REACH Ethiopia, Hawassa, Ethiopia, ${ }^{2}$ Department of International Public Health, Liverpool School of Tropical Medicine, Liverpool, UK, ${ }^{3}$ Royal \\ Tropical Institute, Amsterdam, The Netherlands \\ Keywords: global health \\ https://doi.org/10.29392/joghr.3.e2019027
}

\section{Journal of Global Health Reports}

Vol. 3, 2019

\begin{abstract}
Background
Health extension workers (HEWs) are the implementers of the unique primary health care programme of Ethiopia. They facilitate community participation in maternal health service delivery via the health development army (HDA) and pregnant women forums (PWFs). As part of a quality improvement intervention, HEWs received training, guidance and supervision focused on facilitation of HDA meetings and PWFs. We aimed to assess the effect of the intervention on maternal health service utilization and explore the perceptions of stakeholders regarding efforts to enhance community participation in maternal health.
\end{abstract}

\begin{abstract}
Methods
We conducted a mixed method study in Shebedino woreda (district), Sidama Zone, southern Ethiopia. The research team observed HDA meetings and PWFs (15), conducted in-depth interviews with $32 \mathrm{HEWs}, 8 \mathrm{HEW}$ supervisors and maternal health program managers, and conducted 8 focus group discussions (FGDs) with community members. The interviews and FGDs were recorded, transcribed, translated, coded in Nvivo and thematically analysed. We also collected quantitative data on HDA and PWF participation, antenatal care attendance and skilled delivery and analysed using Excel (Microsoft Inc, Seattle, WA, USA).
\end{abstract}

\section{Results}

The proportion of HDA leaders and pregnant women who attended the HDA and PWF meetings increased by $30.6 \%$ and 36\% respectively, over 18 months of the intervention. The percentage of pregnant women identified and referred by HDA leaders increased from $42 \%$ to $85 \%$, the antenatal care utilization increased from $73.4 \%$ to $77.6 \%$ and skilled delivery increased from $76.7 \%$ to $83.3 \%$,) ( $\mathrm{p}<0.05$ ). From interviews with stakeholders, we found improved awareness about maternal health services and increased health seeking behaviour. However, lack of incentives and reporting formats for HDA leaders, absenteeism and limited support from kebele administrators constrained community participation in maternal health.

\section{Conclusion}

With focused training, guidance and regular supportive supervision, HEWs were able to stimulate and enhance community participation, resulting in better maternal health service utilization in rural communities. HEWs, volunteer HDAs, pregnant women and the wider community have a role to play in quality improvement of maternal health services.

The Alma Ata declaration of 1978 defines primary health care as essential health care that is universally accessible and acceptable at an affordable cost. It focuses on disease prevention and health promotion through community participation and encourages the community to contribute to and maintain their own health. It is believed that commu- nity participation leads to more cost-effective service delivery and increases service utilisation. As communities take greater ownership of health services, these services would become culturally acceptable and responsive to local needs, resulting in increased self-reliance and social awareness in 
the community, and ultimately lead to better health outcomes. ${ }^{1,2}$

In 2004, the government of Ethiopia introduced a community-based initiative called the Health Extension Programme (HEP) to deliver primary health care services. The HEP contains 16 health packages under four main areas: disease prevention and health promotion, personal and environmental hygiene, maternal and child health, and health education (the latter being a cross-cutting theme). The HEP is primarily implemented by health extension workers (HEWs), female residents who are selected by their community and trained for one year. ${ }^{3-5}$ HEWs spend three-quarters of their time on home visits and the rest of the their time they are based in health posts to deliver primary health care. ${ }^{6}$

Maternal and child health are the highest public health priorities in Ethiopia. In 2015, the maternal mortality ratio was 353 per $100,000 .^{7-9}$ This could be explained by factors that are negatively affecting the utilization of existing health services. ${ }^{10}$ In 2016, the national antenatal care (ANC) follow up (defined as at least two follow up during pregnancy of the required four standard visits) and skilled delivery were just $62 \%$ and $26 \%$ respectively. ${ }^{11}$

Studies and national HEP assessment reports show that access to and coverage of maternal and child health services have improved after introduction of the HEP. ${ }^{12-14}$ Community participation has been identified as one of the key drivers of these improvements. ${ }^{15}$ The work of HEWs is extended beyond health posts to communities through the health development army (HDA - a network organized in clusters of five households to one "leader" household) and pregnant women forums (PWFs). ${ }^{16}$ The HDA leaders identify pregnant women in their kebele (village) and refer them to the health posts for ANC services and encourage them to attend PWFs. ${ }^{15}$ The main aim of the PWF is to increase skilled delivery though interactive discussion about pregnancy, danger signs and risks associated with delays in seeking health care. The use of ANC, delivery and postnatal care services is promoted in a peer setting of pregnant women and the importance of birth preparedness and breastfeeding is discussed as well. The discussion is facilitated by HEWs and assisted by midwives from the catchment health centres. ${ }^{17,18}$ An earlier study in Sidama, Southern Ethiopia reported that performance of HEWs and utilization of maternal services was, amongst other factors, influenced by the extent of community participation. ${ }^{19}$

\section{OBJECTIVE}

The aim of this study was to assess the effect of a quality improvement intervention that is enhanced community participation within HDA meetings and PWFs on maternal health service utilization and explore the perceptions and experiences of communities and HEWs of that intervention.

\section{METHODS}

\section{STUDY AREA}

This mixed-methods study was conducted from July 2014 to February 2016 in Shebedino district (woreda) in Sidama zone of southern Ethiopia. The district has a population of
261,271 living in 32 villages. It has one primary hospital and nine health centres. There are 32 health posts and 65 HEWs in the community. The HEWs are supported by 32 HEWs supervisors and 30 midwives from the catchment area health centres.

\section{HEALTH EXTENSION PROGRAMME}

The government of Ethiopia launched innovative health extension programme (HEP) with main focus on preventive and promotive health services to ensure access to primary health care in the community. The HEP is organized under 16 health packages of which maternal and child health is one of the major components. The HEP is implemented by health extension workers (HEWs), female $10^{\text {th }}$ grade completed women who were selected by the community and received one year training about the packages and its implementation. The HEWs are employed, salaried and deployed by the government to function from health post, providing service to catchment population of about five thousand people. Under the HEWs exist health development army leaders that are model households coordinating the health issues of five households under their network, primary responsible for the HEWs and support their community activities. HEWs coordinate the work of HDAs and work with catchment health centre to ensure successful implementation of the health extension packages. However, the function and service delivery depends on the commitment of the HEWs, coordination with the health centre health workers and support from the districts.

\section{THE COMMUNITY PARTICIPATION INTERVENTION}

A baseline assessment was conducted to understand the status of maternal health service delivery in the district, including barriers and facilitators to the role of HEWs. Quality improvement interventions were designed to address the key problems identified, one of which focused on enhancing community participation in maternal health. This intervention addressed weaknesses in the existing community HDA leaders meetings and PWFs by:

1. Providing integrated refresher training for HEWs in facilitation skills during HDA leaders' meetings and PWFs;

2. Strengthening the coordination between 32 health posts and nine health centres;

3. Designing and providing facilitation guides for supervision meetings to health centres and HEWs in the catchment area; and

4. Facilitating monthly group supervision meetings for HEWs at the health centres.

\section{DATA MANAGEMENT}

Qualitative and quantitative data collection methods were employed to explore perceptions and experiences of communities and HEWs regarding efforts to enhance community participation with both types of community meetings; and to assess outputs and outcomes of the intervention. The main variables included the percentage of health posts conducting monthly PWFs or HDA leaders' meetings, meet- 
Table 1. Summary of the data collection tools, types, sources and process

\begin{tabular}{|c|c|c|c|}
\hline Tool & Types & Data sources & Process of data collection \\
\hline \multirow[t]{2}{*}{ Data tracking } & $\begin{array}{l}\text { HMIS } \\
\text { maternal } \\
\text { health data }\end{array}$ & $\begin{array}{l}\text { District health office, health centres and } \\
\text { health posts }\end{array}$ & $\begin{array}{l}\text { Baseline and endline, data collected from } 2 \\
\text { health centres and } 9 \text { health posts }\end{array}$ \\
\hline & $\begin{array}{l}\text { Output } \\
\text { indicators }\end{array}$ & Health posts & $\begin{array}{l}4 \text { times, once in a quarter over a year, data } \\
\text { collected from } 9 \text { health posts }\end{array}$ \\
\hline Observation & & $\begin{array}{l}\text { Community meetings (HDA leaders' } \\
\text { meetings and PWFs) }\end{array}$ & $\begin{array}{l}15 \text { meetings over a year ( } 5 \text { groups } \\
\text { followed: at the beginning, after half a year } \\
\text { and after } 1 \text { year) }\end{array}$ \\
\hline \multirow[t]{3}{*}{ Interviews } & $\begin{array}{l}\text { Motivation } \\
\text { IDIs }\end{array}$ & HEWs & $\begin{array}{l}8 \mathrm{HEW} \text { s were interviewed, } 3 \text { times over a } \\
\text { year }\end{array}$ \\
\hline & $\begin{array}{l}\text { Intervention } \\
\text { IDIs HEWs }\end{array}$ & HEWs & $\begin{array}{l}8 \mathrm{HEWs} \text { were interviewed at the end of } \\
\text { the year of implementation }\end{array}$ \\
\hline & KIIs & $\begin{array}{l}\text { Maternal health programme coordinators } \\
\text { from woreda, health centre heads and HEW } \\
\text { supervisors }\end{array}$ & $\begin{array}{l}6 \text { Male and } 2 \text { Female were interviewed at } \\
\text { the end of the year of implementation }\end{array}$ \\
\hline FGDs & & Community & $\begin{array}{l}4 \text { male and } 4 \text { female FGDs were conducted } \\
\text { at the end of the year of implementation }\end{array}$ \\
\hline
\end{tabular}

FGD - focus group discussion, HEW - health extension worker, IDI - indepth interview, HDA - health development army, KII - key informant interviews, PWF - pregnant women forums

ing attendance, and longer term outcomes on maternal health service utilization, as tracked from routine reporting systems. Observation of HDA leaders' meetings and PWFs was conducted over time in randomly selected health posts. This was combined with in-depth interviews (IDIs) with HEWs and their supervisors and maternal health program managers, and focus group discussions (FGDs) with female and male community members at the end of the intervention period (Table 1).

\section{DATA COLLECTION}

Data were collected from routine registers, reports, minute books of HDA leaders' meetings and PWFs of nine health posts. The variables included the proportion of registered pregnant women that was identified by HDA leaders, the proportion of pregnant women who attended the PWFs and HDA leaders who attended the HDA leaders' meetings. The maternal health indicators assessed were ANC attendance and facility delivery.

\section{OBSERVATIONS OF COMMUNITY MEETINGS}

HDA leaders' meetings and PWFs were observed by two researchers. Two HDAs meetings and three PWFs were repeatedly followed by researchers, at the baseline, midline and endline of the intervention period. A total of six HDA leaders' meetings and nine PWFs were observed during the intervention period. The observations captured the feedback of the community about maternal health services. After the meetings, the researchers provided feedback to the HEWs about the mode of facilitation, discussion and participation of attendants.

\section{IN-DEPTH INTERVIEWS}

HEWs were interviewed about factors that influenced their motivation, specifically about how the community partic- ipation intervention influenced their work. The IDIs were conducted at the health post, and participants were interviewed based on their motivation status (unpublished data) - four highly motivated and four less motivated HEWs were interviewed and followed up, resulting in 24 IDIs in three rounds. At the end of the intervention, eight extra IDIs were conducted with HEWs to obtain their perspectives on how the intervention affected their work, their opinions about it, and what worked well and what did not work well and why. In addition, eight key informant interviews (KIIs) were conducted with health managers, two with staff from the district health office, two from health centres and four with HEW supervisors.

\section{FOCUS GROUP DISCUSSIONS}

Eight FGDs (each consisting of 8 - 10 participants) were conducted, four with male and four with female community members. The majority of women were between 30 - 34 years and they comprised of HDA leaders, pregnant and lactating women, women who gave birth in the past year and their relatives. The majority of men were between 35 39 years and they comprised of kebele administrators, religious leaders, influential people and husbands of pregnant women, lactating women and/or women who gave birth in the past year. The FGDs were conducted in the community where it was convenient for the participants.

\section{RECRUITMENT OF PARTICIPANTS}

The recruitment process was done with full engagement and support of relevant stakeholders in the study area. These were the head of the Sidama zone Health Department, HEP coordinators of the district health office, supervisors of HEWs in the nine health centres and 32 kebele administrators. They were engaged in identifying, contacting potential study participants and facilitating their participation in their respective levels or areas. Participants were re- 
cruited after obtaining informed consent to participate in the study.

\section{QUALITY ASSURANCE}

Researchers were trained on qualitative data collection procedures in relation to this study. The topic guides were drafted in English and translated in in Amharic and then in the Sidama language for participants unable to understand Amharic. Back translation was conducted for quality assurance. The topic guides were piloted in a different district and small adjustments were made to clarify questions and probes. During data collection, regular debriefing meetings were held to discuss preliminary findings and data saturation. ${ }^{20}$

\section{DATA ANALYSIS}

For each meeting observation, a summary report was written and independently read by three researchers, from which key themes were drawn jointly. All IDIs and FGDs were digitally recorded, transcribed and translated into English. A sample of transcripts was randomly checked against the recordings to ensure data quality. The transcripts were read by three researchers to identify key themes and to elaborate on the initial deductive code frame based on themes in the topic guides. Transcripts were coded using NVivo (version 10) software, emerging themes were discussed and added, and the coding was refined. The coded transcripts were further analysed and summarized in narratives for each theme and sub-theme. For quantitative data, descriptive analysis was conducted using Excel.

\section{ETHICAL CONSIDERATIONS}

Ethical approval for this study was provided by the Research Ethics Committee of Liverpool School of Tropical Medicine, UK and the Regional Health Bureau of the Southern Nations, Nationalities, and Peoples Region of Ethiopia. We also obtained support letters from the Sidama zone health department and district health offices to ensure permission and cooperation from health institutions, health workers, HEWs and community members. Informed consent was obtained from the study participants.

\section{RESULTS}

The intervention resulted in increased engagement of HDA leaders, participation of pregnant women in PWFs and contributed to increased utilization of maternal health services.

The exploration of the perceptions of stakeholders who were involved in the intervention yielded the following major themes: attendance, content, facilitation and general benefits and challenges of the HDA leaders' meetings and PWFs.

\section{ATTENDANCE OF COMMUNITY MEETINGS BY HDA LEADERS AND PREGNANT WOMEN}

The proportion of HDA leaders attending the meetings increased from $12.4 \%$ at baseline to $43 \%$ at endline $(\mathrm{p}<0.05)$. As shown in table 2, the proportion of pregnant women attending the PWFs increased from $47 \%$ at baseline to $83 \%$ at endline $(\mathrm{P}<0.05)$. The increased attendance of both the HDA leaders' meetings and the PWFs was confirmed by all study participants.
"Generally there is good improvement in community en- gagement in PWF and HDA meetings; especially there is increased and visible participation of women in PWFs...they also discuss how to identify danger signs dur- ing pregnancy, labour and the postnatal period by using the family health guide." (Interview with HEW, endline)

The PWFs were better attended than the HDA leaders meeting. This could be due to non-willingness of HDA leaders as some of them sought financial incentives that were not available.

\section{CONTENT OF COMMUNITY MEETINGS: HDA LEADERS' MEETINGS AND PWFS}

The content of community meetings varied based on the type of the meeting. The agenda of discussion during the PWF was about pregnancy-related issues and maternal health services, such as the importance of ANC, institutional delivery and postnatal care. The agenda of the HDA leaders' meeting had a broader health focus, as shown in the quote below:

\begin{abstract}
"We have a meeting once in a month with HDA and talk about health issues like institutional delivery, vaccination, exclusive breast feeding till six months of age, supplementary feeding after the age of six months, environmental hygiene, personal hygiene and HIV testing. Since HDAs are within the community, they communicate and help in bringing malnourished children, help pregnant mothers come for vaccination to the health post etc." (HEW interview, baseline)
\end{abstract}

\section{FACILITATION OF AND COMMUNICATION DURING HDA LEADERS' MEETINGS AND PWFS}

HDA leaders' meetings were only supported by HEWs, while midwives from catchment health centers facilitated PWFs together with HEWs. Family health facilitation guide cards were used to illustrate pictures for the pregnant women. "We teach about danger signs using the family health
guidance by showing pictures of danger signs which occur
during pregnancy, so that women get in-depth under-
standing of possible problems." (HEW interview, endline)

In the first observations, we found that the HEWs used a teaching mode and the participants were mostly silent. As a result, it was difficult to understand the view of the participants. However, over time, the mode of discussion improved to two-way communication and women were encouraged to participate and raise cultural or personal issues which were the main barriers to seek maternal health services. 
Table 2. The summary of key achievements of quality improvement intervention in Shebedino district, Sidama zone, southern Ethiopia

\begin{tabular}{|c|c|c|c|c|c|c|c|c|c|c|}
\hline \multirow[t]{3}{*}{ Health centres } & \multicolumn{10}{|c|}{ Quality improvement intervention activities } \\
\hline & \multicolumn{2}{|c|}{$\begin{array}{c}\text { HDA leaders attended } \\
\text { monthly meeting }\end{array}$} & \multicolumn{2}{|c|}{ PW attended PWF } & \multicolumn{2}{|c|}{$\begin{array}{c}\text { PW Identified by HDA } \\
\text { leaders }\end{array}$} & \multicolumn{2}{|c|}{ ANC coverage } & \multicolumn{2}{|c|}{ Skilled delivery coverage } \\
\hline & Baseline & End line & Baseline & End line & Baseline & End line & Baseline & End line & Baseline & End line \\
\hline Abela lida Health Center & $\begin{array}{c}18 / 205 \\
(9 \%)\end{array}$ & $\begin{array}{c}117 / 205 \\
(57 \%)\end{array}$ & $\begin{array}{c}178 / 389 \\
(46 \%)\end{array}$ & $\begin{array}{c}249 / 445 \\
(56 \%)\end{array}$ & $\begin{array}{l}20 / 72 \\
(28 \%)\end{array}$ & $\begin{array}{l}80 / 84 \\
(95 \%)\end{array}$ & $\begin{array}{l}189 / 265 \\
(71.3 \%)\end{array}$ & $\begin{array}{l}186 / 245 \\
(76.0 \%)\end{array}$ & $\begin{array}{l}273 / 269 \\
(101.5)^{*}\end{array}$ & $\begin{array}{l}269 / 267 \\
(101 \%)^{*}\end{array}$ \\
\hline Morocho Health Center & $\begin{array}{c}0 / 355 \\
(0 \%)\end{array}$ & $\begin{array}{c}64 / 355 \\
(18 \%)\end{array}$ & $\begin{array}{c}91 / 265 \\
(34 \%)\end{array}$ & $\begin{array}{c}287 / 287 \\
(100 \%)\end{array}$ & $\begin{array}{c}43 / 163 \\
(26 \%)\end{array}$ & $\begin{array}{c}142 / 197 \\
(72 \%)\end{array}$ & $\begin{array}{l}249 / 300 \\
(83.0 \%)\end{array}$ & $\begin{array}{l}237 / 308 \\
(77.0 \%)\end{array}$ & $\begin{array}{l}159 / 309 \\
(51.4 \%)\end{array}$ & $\begin{array}{c}237 / 315 \\
(79 \%)\end{array}$ \\
\hline Fura Health Center & $\begin{array}{l}88 / 397 \\
(22.2 \%)\end{array}$ & $\begin{array}{c}127 / 397 \\
(32 \%)\end{array}$ & $\begin{array}{c}56 / 119 \\
(47 \%)\end{array}$ & $\begin{array}{c}106 / 128 \\
(83 \%)\end{array}$ & $\begin{array}{l}52 / 92 \\
(56 \%)\end{array}$ & $\begin{array}{l}88 / 98 \\
(88 \%)\end{array}$ & $\begin{array}{c}207 / 270 \\
(76.7 \%)\end{array}$ & $\begin{array}{l}215 / 262 \\
(82.0 \%)\end{array}$ & $\begin{array}{l}169 / 168 \\
(100.6 \%)\end{array}$ & $\begin{array}{c}241 / 264 \\
(91 \%)\end{array}$ \\
\hline Gebire kiristos Health center & $\begin{array}{c}70 / 348 \\
(20 \%)\end{array}$ & $\begin{array}{c}181 / 348 \\
(52 \%)\end{array}$ & $\begin{array}{c}79 / 182 \\
(43 \%)\end{array}$ & $\begin{array}{c}148 / 203 \\
(73 \%)\end{array}$ & $\begin{array}{c}84 / 210 \\
(40 \%)\end{array}$ & $\begin{array}{c}188 / 244 \\
(77 \%)\end{array}$ & $\begin{array}{l}216 / 298 \\
(72.5 \%)\end{array}$ & $\begin{array}{l}272 / 298 \\
(91.0 \%)\end{array}$ & $\begin{array}{c}202 / 299 \\
(67.6 \%)\end{array}$ & $\begin{array}{c}247 / 294 \\
(92 \%)\end{array}$ \\
\hline Telamo Health Center & $\begin{array}{c}0 / 293 \\
(0 \%)\end{array}$ & $\begin{array}{c}173 / 293 \\
(59 \%)\end{array}$ & $\begin{array}{c}59 / 121 \\
(49 \%)\end{array}$ & $\begin{array}{c}125 / 137 \\
(91 \%)\end{array}$ & $\begin{array}{c}66 / 137 \\
(48 \%)\end{array}$ & $\begin{array}{c}132 / 142 \\
(93 \%)\end{array}$ & $\begin{array}{l}158 / 217 \\
(72.8 \%)\end{array}$ & $\begin{array}{l}186 / 211 \\
(88.0 \%)\end{array}$ & $\begin{array}{c}211 / 219 \\
(96.3)\end{array}$ & $\begin{array}{c}207 / 214 \\
(97 \%)\end{array}$ \\
\hline Dobe Toga Health Center & $\begin{array}{c}178 / 423 \\
(42 \%)\end{array}$ & $\begin{array}{c}233 / 423 \\
(55 \%)\end{array}$ & $\begin{array}{c}96 / 133 \\
(72 \%)\end{array}$ & $\begin{array}{c}142 / 142 \\
(100 \%)\end{array}$ & $\begin{array}{c}71 / 142 \\
(50 \%)\end{array}$ & $\begin{array}{c}138 / 155 \\
(89 \%)\end{array}$ & $\begin{array}{l}187 / 300 \\
(62.3 \%)\end{array}$ & $\begin{array}{l}129 / 243 \\
(53.0 \%)\end{array}$ & $\begin{array}{l}173 / 300 \\
(57.7 \%)\end{array}$ & $\begin{array}{c}248 / 294 \\
(84 \%)\end{array}$ \\
\hline Mero Kawado Health Center & $\begin{array}{c}0 / 266 \\
(0 \%)\end{array}$ & $\begin{array}{c}141 / 266 \\
(53 \%)\end{array}$ & $\begin{array}{c}77 / 118 \\
(65 \%)\end{array}$ & $\begin{array}{c}133 / 133 \\
(100 \%)\end{array}$ & $\begin{array}{c}82 / 135 \\
(61 \%)\end{array}$ & $\begin{array}{c}100 / 143 \\
(70 \%)\end{array}$ & $\begin{array}{c}169 / 219 \\
(77.2) \%\end{array}$ & $\begin{array}{l}107 / 198 \\
(54.0 \%)\end{array}$ & $\begin{array}{c}164 / 207 \\
(79.2 \%)\end{array}$ & $\begin{array}{c}160 / 204 \\
(78 \%)\end{array}$ \\
\hline Galuko Hireye Health Center & $\begin{array}{c}33 / 543 \\
(6 \%)\end{array}$ & $\begin{array}{c}76 / 543 \\
(14 \%)\end{array}$ & $\begin{array}{c}167 / 281 \\
(59 \%)\end{array}$ & $\begin{array}{c}265 / 312 \\
(85 \%)\end{array}$ & $\begin{array}{c}47 / 127 \\
(37 \%)\end{array}$ & $\begin{array}{c}124 / 136 \\
(91 \%)\end{array}$ & $\begin{array}{c}185 / 213 \\
(86.8 \%)\end{array}$ & $\begin{array}{c}164 / 210 \\
(78.0 \%)\end{array}$ & $\begin{array}{l}167 / 216 \\
(77.3 \%)\end{array}$ & $\begin{array}{c}175 / 216 \\
(81 \%)\end{array}$ \\
\hline Dulecha Health Center & $\begin{array}{c}0 / 284 \\
(0 \%)\end{array}$ & $\begin{array}{c}165 / 284 \\
(58 \%)\end{array}$ & $\begin{array}{l}16 / 118 \\
(13.6 \%)\end{array}$ & $\begin{array}{c}126 / 126 \\
(100 \%)\end{array}$ & $\begin{array}{c}41 / 119 \\
(34 \%)\end{array}$ & $\begin{array}{c}107 / 123 \\
(87 \%)\end{array}$ & $\begin{array}{c}213 / 333 \\
(64.0 \%)\end{array}$ & $\begin{array}{c}289 / 325 \\
(89.0 \%)\end{array}$ & $\begin{array}{c}262 / 335 \\
(78.2 \%)\end{array}$ & $\begin{array}{c}213 / 330 \\
(65 \%)\end{array}$ \\
\hline $\begin{array}{l}\text { Shebedino district summary }-\mathrm{n} / \mathrm{N} \text {, } \\
\%\end{array}$ & $\begin{array}{c}387 / \\
3114 \\
(12.4 \%)\end{array}$ & $\begin{array}{l}1337 / \\
3114 \\
(43 \%)\end{array}$ & $\begin{array}{l}819 / \\
1726 \\
(47 \%)\end{array}$ & $\begin{array}{l}1581 / \\
1913 \\
(83 \%)\end{array}$ & $\begin{array}{l}506 / 1197 \\
(42 \%)\end{array}$ & $\begin{array}{l}1099 / 1293 \\
(85 \%)\end{array}$ & $\begin{array}{l}1773 / \\
2415 \\
(73.4 \%)\end{array}$ & $\begin{array}{l}1785 / \\
2300 \\
(77.6 \%)\end{array}$ & $\begin{array}{l}1780 / \\
2322 \\
(76.7 \%)\end{array}$ & $\begin{array}{c}1997 / \\
2398 \\
(83.3 \%)\end{array}$ \\
\hline
\end{tabular}

ANC - antenatal care, PW -pregnant woman, PWF - pregnant woman's forum

"The number of pregnant women attending the PWF exceeded the number of expected pregnant women. This could be explained by pregnant women attending the PWF from outside the health post's catchment area, or it could be that the number of expected pregnant women was estimated too low in the health management information system. 


\section{BENEFITS OF COMMUNITY MEETINGS}

\section{KNOWLEDGE AND AWARENESS}

The majority of interviewed participants reported that the knowledge and awareness of women about maternal health services improved as a result of the PWFs and HDA efforts. For example, women came to know danger signs that may occur during labour, delivery and post-delivery.

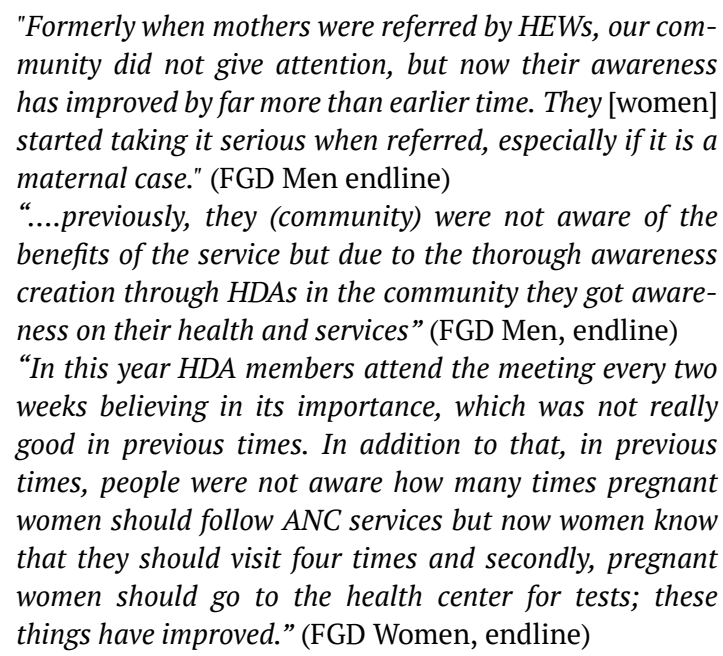

Strengthened participation through PWFs and HDA leaders' meetings was reported to contribute to increased awareness of maternal health service and improved attitudes of community members, as described below.

\begin{abstract}
"We are more successful on community participation because as there are only 2 or 3 HEWs at the health post, it is hard for them to reach the whole kebele. Women involved in PWFs and HDAs helped much in influencing the community's awareness which in turn results in change of the community's attitude". (HEW supervisor interview, endline)
\end{abstract}

\section{HEALTH SEEKING BEHAVIOR AND SERVICE UTILIZATION}

Both PWFs and HDA leaders' meetings helped women to address socio-cultural factors that influenced maternal health seeking, like trusting traditional birth attendants and opting for home delivery. As a result, the women participating were reported to have increased tendency of seeking health care and giving birth at the health facilities. This was confirmed by the quantitative data: The ANC utilization figures increased from $73.4 \%$ to $77.6 \%$ and the institutional skilled delivery rate increased from $76.7 \%$ to $83.3 \%$ (table 2). HEWs reported that both community meetings helped to avert potential maternal and new born deaths.

\footnotetext{
"To increase use of maternal health services, the PWF is the good method, because at the meeting many important ideas are shared. The PWF prevents death of mothers. It clearly helps mothers to know the importance of delivering at the health facility over home delivery. Mothers now know the phone number of the ambulance driver and call it at the time of labour; that is because of knowledge gained during the PWF." (HEW interview, endline)

“...previously pregnant mothers never used to reveal their pregnancy and attend ANC because of cultural influence,
}

we used to know if they are pregnant after their abdomen gets bigger like after 5th month or when they come for delivery. But now they come early and some of them tell us about their pregnancy and requests us for urine test..." (HEW interview, endline)

In one kebele, an HDA leader reported that advising women was difficult previously, but easier after the training and support from the intervention:

"My village is behind the hill, initially I was tired a lot, be-
cause mothers were not voluntarily going for ANC visits
and other services, but now though it is far from health
posts they are attending the PWF and also getting the
ANC services, because they understand the importance,
because of that they saved us from tiredness." (FGD
Women, endline)

The husbands who participated in FGDs also explained that the HDA has played a role in stimulating health seeking behavior:

$$
\begin{aligned}
& \text { “...we, Sidama husbands, used to let our wives stay in- } \\
& \text { doors, but now we send them for ANC service immediately } \\
& \text { when they are pregnant. And we advise pregnant women } \\
& \text { in our community to visit the health post as well...”(FGD } \\
& \text { Men, endline) }
\end{aligned}
$$

\section{IDENTIFICATION OF PREGNANT WOMEN AND REFERRALS BY HDA LEADERS}

Tracking data showed that the percentage of pregnant women who were identified and referred by HDA leaders from the households increased from $42 \%$ to $85 \%$ (table 2). Participants of interviews and FGDs confirmed that the HDA had a large role in stimulating health seeking and maternal health service utilization, by tracing absentees from ANC and identifying pregnant women and referring them for delivery.
"The HDA is always identifying pregnant women. When there are referral cases, they give a call to HEWs, and then we go to their home with an ambulance. When there is a new pregnancy they inform to the leader of the team, then the leader would bring her to HEWs ${ }^{* * * * * * * * * *}$ (HEW inter- view, endline)

\section{CHALLENGES OF COMMUNITY MEETINGS}

The main challenges of PWFs and HDA leaders' meetings were incentive-seeking by some HDA leaders and absenteeism from the sessions due to distance and workload. In addition, lack of reporting formats affected HEWs' capacity to track performance and effectiveness.

\section{INCENTIVES}

Most HEWs explained challenges with HDA leaders' meetings, because some HDA leaders expected to receive financial incentives to their contribution.

"These HDA leaders are previous voluntary community health workers. These women previously got incentives once in three or six months and have such habit, but now days they get nothing at all. These people make rumour expecting incentives and say HEWs are getting benefits for 
them, letting us to work for free." (HEW interview, endline)

\section{ABSENTEEISM FROM THE MEETINGS OF HDA LEADERS AND PREGNANT WOMEN}

Some HEWs mentioned that absenteeism from the community meetings happened due to distance and household responsibilities of pregnant women or HDA leaders.

\section{"There is a problem of absentees, all participants would not be present all time due to various reasons, and some are claiming the distance, different personal and social is- sues. Some are disinterested to participate. We are plan- ning to arrange the meeting place at different sites as a so- lution." (HEW interview, baseline)}

Health workers in one of the health centres committed themselves to contribute money for PFWs to provide tea and coffee ceremonies during the meetings. The attendance of women in PWFs in the health posts under this health centre was better than in the other areas.

\begin{abstract}
"We, all our catchment health centre staff, contribute 10 birr per month from our salary. This is divided into four health posts organized by a committee established for this purpose. We provide soap for mothers from our contributed budget." (HEW interview, endline)
\end{abstract}

\section{LACK OF REPORTING FORMATS FOR HDA LEADERS}

HEWs mentioned that they collected reports from the leaders of the HDA, but the reporting was verbal. As a result, it was not possible to track the effort of HDA members over time and also to compare one team with another.

"HDA leaders are reporting their performance monthly though it is a verbal report, due to the absence of a reporting format." (HEW interview, endline)

\section{LIMITED SUPPORT FROM THE KEBELE ADMINISTRATION}

HEWs are accountable to the kebele administration. The kebele administration is expected to support HEWs and evaluate the performance of the HDA and PWFs. Some HEWs explained that they received support, but the majority of HEWs explained that for the kebele administrators, the health sector is not always their concern due to competing priorities.

\section{"...sometimes there is work load on kebele leaders because they work on agriculture, education and other tasks. These make it difficult for them to consistently coordinate with every HDA..." (HEW interview, baseline)}

Many HEWs and health system staff reported that support from the kebele on health sector services was not visible, as it is in the agriculture sector, mainly because of a lack of incentives.

"Kebele leaders give priority to the agricultural sector and they don't think that the health sector has a problem and they put the health sector burden on us [HEWs]. Kebele leaders in one or another way get information/new things to be delivered to the community and they work for limited time (one or two days) with us. They don't continue their support. So, to avoid such breaks on supporting us it is better providing certain incentives for them that make them to work with us." (HEW interview, endline)

\section{DISCUSSION}

Bringing health services closer to the community has achieved success in improving health outcomes, and this has been found to be the case also in Ethiopia. However, community participation as declared during the Alma Ata declaration needs continuous investment to ensure access to, and utilization of, primary health services. Structures through which community participation takes place, such as the HDA and the PWF in Ethiopia, should be in place and it is important to identify which factors hinder or facilitate their functionality. We report how a relatively simple intervention, including the introduction of training materials and guides for HEWs on facilitation of community participation and regular monitoring, within the existing community health system, contributed to increased community participation and shows promising results to utilization of ANC and delivery services. We also identified challenges that need to be addressed for better performance.

Close-to-community health providers, such as HEWs, are believed to be able to facilitate community participation, thereby improving community health seeking behaviour and increasing service utilization. ${ }^{21}$ HEWs and HDA leaders play a key role in linking communities to the health sector. They are strategically placed to understand the context of the community: they live within the community, speak their local language and understand the culture. Other studies have shown that socio-cultural factors play a large role in pregnant women's maternal health seeking behaviour ${ }^{10,22-24}$; therefore, community meetings like the HDA leaders' meeting and the PWF, facilitated by HEWs, can provide good platforms for discussing barriers to seek care and increasing awareness on the importance to utilize maternal health services.

The mere existence of community structures and policy provisions is not sufficient: it is the active participation of women and the community at large that have contributed to improved access and service utilization in this intervention study. Structures like the HDA and the PWF should be placed in a functional health system, which provides HEWs a working environment to effectively facilitate and promote community participation, and which generally enhances communities' trust in the system. ${ }^{25}$

Long-term implementation requires continuous investment in HEWs' roles in facilitating community participation. The role of HEWs should, besides the more technical tasks related to disease specific programmes, keep on having a focus on triggering community participation and social change. ${ }^{26,27}$ Sustainable participation of communities might also need strategies to address challenges related to volunteerism, as raised by several stakeholders during the interviews. HDA leaders asked for financial incentives, partly because some of them were (different types of) volunteers in the past and used to receive allowances. An ethnographic study in Addis Ababa also found that among volunteers working for a non-governmental organization, uncertainty about achieving basic food security and im- 
proved socioeconomic status for themselves and their families, in a context of high unemployment, made them request for remuneration. ${ }^{28}$ Although HDA leaders have a designated role in assisting HEWs and facilitating community participation, the HDA has been introduced as a system in which there is no financial compensation, as ultimately, all households should be part of the HDA. Alternatively, as found in this study, provision of limited material incentives through a joint responsibility of actors in the health sector and community could motivate volunteers to participate.

Effective community meetings need facilitators who are equipped with communication and facilitation skills. Participatory facilitation skills can increase the interest of the community as communication shifts from a one person lecture to two way communication; and there is as such a higher chance that the key challenges of the clients, or the community at large, are addressed. Participatory action research conducted in Uganda has demonstrated the contribution of community in improving birth preparedness and access to health facilities in rural communities. Reviews of similar activities have demonstrated improved maternal health outcomes in sub Saharan Africa and Asian countries. ${ }^{29-32}$ This requires observation and support, including supervision and continuous training for HEWs, so that they can learn in the process and function as expected. This could be improved by providing monitoring tools for the HEWs, their supervisors and kebele administrators.

Community structures, embedded in a supportive health system, could contribute to improved maternal health service utilization as shown in this study. The comprehensive and inclusive approach, where the pregnant women, HDA leaders, local administration and the HEWs and professional health workers are working for a common goal, contributed to the success of the intervention. However, the variable support of the kebele leaders, also found in an earlier study, ${ }^{19}$ and lesser participation of HDA leaders could be limiting the effectiveness in the future.

While the study results give an indication that improved community participation through HDA leaders' meetings and PWFs could contribute to improved service utilization, we are not able to prove the effectiveness of the intervention at scale. This will remain a problem, as maternal service utilization is affected by multiple actors and contextual factors in the complexity of the health system, including the community. 33

In conclusion, engaging communities through a facilitating role of HEWs contributed to enhanced community participation and improved utilization of maternal health services in Shebedino woreda, Sidama zone in southern Ethiopia. This was ensured by the continued effort to strengthen health centre and health post link and group supervision at catchment health centres. This could be sustained, when the health system keeps on investing in and supporting the HDA and PWFs and enhancing the facilitating role of HEWs. There is great potential to maximize their contribution towards improving maternal health-seeking behaviour, in particular related to skilled, institutional delivery. The lessons learned from this study could be scaled up and used in other settings in the country due to the existing decentralized health system and functional community structures. Embedding the intervention into the health system - from a project-led to an intervention at scale needs continued effort and partnership. This requires working with the health system from the design to implementation, shifting leadership of project activities to health workers and policy makers and ensuring its effective implementation through continued review of activities and sharing experiences. Further studies are required to understand sustainability and cost-effectiveness of such interventions in the future.

\section{GEOLOCATION}

Ethiopia.

\section{ACKNOWLEDGEMENTS}

The authors sincerely thank REACH Ethiopia teams, REACH OUT consortium, HEWs, health workers and policy makers in the study area.

\section{FUNDING INFORMATION}

This programme has received funding from the European Union Seventh Framework Programme ([FP7/2007-2013] [FP7/2007-2011]) under grant agreement number 306090.

\section{COMPETING INTERESTS}

The authors have completed the Unified Competing Interest form at http://www.icmje.org/coi_disclosure.pdf (available on request from the corresponding author) and declare no conflicts of interest.

\section{DISCLAIMERS}

The study presented in this paper is part of the REACHOUT programme. This publication reflects only the authors' views, and the European Union is not liable for any use that may be made of the information contained herein.

\section{CORRESPONDENCE TO:}

Daniel G. Datiko

REACH Ethiopia

Box 303

Hawassa

Ethiopia

danieljohn42@yahoo.com 


\section{REFERENCES}

1. USSR. International Conference on Primary Health Care, Alma-Ata; 1978.

\section{WHO, UNICEF. Antenatal Care in Developing} Countries: Promises, Achievements and Missed Opportunities. An Analysis of Trends, Levels and Differentials, 1990-2001. World Health Organization; 2003.

3. Ministry of Health. Health Extension Education Centre. Health Extension Programme in Ethiopia; 2007.

4. Koblinsky M, Tain F, Gaym A, Karim A, Carnell M, Tesfaye S. Responding to the maternal health care challenge: The Ethiopian Health Extension Program. Ethiop J Health Dev. 2010;24(SPEC. ISSUE 1):105-109. doi:10.4314/ejhd.v24i1.62951

5. Federal Ministry of Health of Ethiopia. National Reproductive Health Strategy 2006 - 2015; 2006.

6. Federal Ministry of Health. Health Extension Programme in Ethiopia; 2007.

7. World Health Organization. Optimizing Health Worker Roles to Improve Access to Key Maternal and Newborn Health Interventions through Task Shifting. WHO; 2012.

8. Federal Ministry of Health of Ethiopia. Health Sector Development Programme IV 2010/11 - 2014/ $15 ; 2010$.

9. WHO, UNFPA, World Banks Group, United Nations Population Division. Trends in Maternal Mortality: 1990 to 2015.

10. Tarekegn SM, Lieberman LS, Giedraitis V. Determinants of maternal health service utilization in Ethiopia: analysis of the 2011 Ethiopian Demographic and Health Survey. BMC Pregnancy Childbirth. 2014;14(1):161. doi:10.1186/1471-2393-1 4-161

11. Federal Democratic Republic of Ethiopia. Ethiopia Demographic and Health Survey 2016. CSA ICF; 2017.

12. Wolde M, Morankar S, Deressa AA, Schaay N, Sanders D, Labonte R. Contribution of the health service extensionprogram to improve coverage and comprehensiveness of primary health care services in Jimma Zone, Southwest Ethiopia. In: 13th World Congress on Public Health World Health Organization, Addis Ababa, Ethiopia.
13. Center for National Health Development in Ethiopia, The Earth Institute at Columbia University, UNICEF, WHO. Evaluation of health extension program: Rural Ethiopia; 2010.

14. Medhanyie A, Spigt M, Kifle Y, et al. The role of health extension workers in improving utilization of maternal health services in rural areas in Ethiopia: a cross sectional study. BMC Health Serv Res. 2012;12(1):352. doi:10.1186/1472-6963-12-352

15. Federal Ministry of Health of Ethiopia. Health Sector Transformation Plan (2015/16-2019/20); 2015.

16. Federal Ministry of Health. Health Extension workers in Ethiopia, 2014; 2014.

17. WHO, UNICEF, UNFPA, World Bank. Trends in Maternal Mortality 1990-2015. WHO; 2015.

18. Bedford J, Gandhi M, Admassu M, Girma A. 'A normal delivery takes place at home': A qualitative study of the location of childbirth in rural Ethiopia. Matern Child Health J. 2013;17(2):230-239. doi:10.100 7/s10995-012-0965-3

19. Kok MC, Kea AZ, Datiko DG, et al. A qualitative assessment of health extension workers' relationships with the community and health sector in Ethiopia: opportunities for enhancing maternal health performance. Hum Resour Health. 2015;13(1):80. doi:1 0.1186/s12960-015-0077-4

20. Saunders B, Sim J, Kingstone T, et al. Saturation in qualitative research: exploring its conceptualization and operationalization. Qual Quant. 2018;52(4):1893-1907. doi:10.1007/s11135-017-057 $4-8$

21. Wagner AL, Porth JM, Bettampadi D, Boulton ML. Have community health workers increased the delivery of maternal and child healthcare in India? J Public Health (Oxf). 2017;40(2):e164-e170. doi:10.109 3/pubmed/fdx087

22. Islam MR, Odland JO. Determinants of antenatal and postnatal care visits among Indigenous people in Bangladesh: a study of the Mru Community. Rural Remote Health. 2011;11:1672.

23. Tsegay Y, Gebrehiwot T, Goicolea I, Edin K, Lemma H, Sebastian MS. Determinants of Antenatal Care, Institutional Delivery and Skilled Birth Attendant Utilization in Samre Saharti District, Tigray, Ethiopia. Published online 2010. 
24. Teferra AS, Alemu FM, Woldeyohannes SM. Institutional delivery service utilization and associated factors among mothers who gave birth in the last 12 months in Sekela District, North West of Ethiopia: a community - based cross sectional study. BMC Pregnancy Childbirth. 2012;12(1):74. doi:10.118 6/1471-2393-12-74

25. Kok MC, Broerse JEW, Theobald S, Ormel H, Dieleman M, Taegtmeyer M. Performance of community health workers: situating their intermediary position within complex adaptive health systems. Hum Resour Health. 2017;15(1):59. doi:10.11 86/s12960-017-0234-Z

26. Pérez LM, Martinez J. Community health workers: social justice and policy advocates for community health and well-being. Am J Public Health. 2008;98(1):11-14. doi:10.2105/ajph.2006.100842

27. Sabo S, Ingram M, Reinschmidt KM, et al. Predictors and a framework for fostering community advocacy as a community health worker core function to eliminate health disparities. Am J Public Health. 2013;103(7):e67-e73. doi:10.2105/ajph.2012.301108

28. Maes K. Volunteerism or labor exploitation? Harnessing the volunteer spirit to sustain AIDS treatment programs in urban Ethiopia. Hum Organ. 2012;71(1):54-64. doi:10.17730/humo.71.1.axm39467 485m22w4
29. Lunsford SS, Fatta K, Stover KE, Shrestha R. Supporting close-to-community providers through a community health system approach: case examples from Ethiopia and Tanzania. Hum Resour Health. 2015;13(1):12. doi:10.1186/s12960-015-0006-6

30. Sarin E, Lunsford SS. How female community health workers navigate work challenges and why there are still gaps in their performance: a look at female community health workers in maternal and child health in two Indian districts through a reciprocal determinism framework. Hum Resour Health. 2017;15(1):44. doi:10.1186/s12960-017-022 $\underline{2-3}$

31. Ekirapa-Kiracho E, Namazzi G, Tetui M, et al. Unlocking community capabilities for improving maternal and newborn health: participatory action research to improve birth preparedness, health facility access, and newborn care in rural Uganda. BMC Health Serv Res. 2016;16(S7). doi:10.1186/s1291 3-016-1864-X

32. Jennings MC, Pradhan S, Schleiff M, et al. Comprehensive review of the evidence regarding the effectiveness of community-based primary health care in improving maternal, neonatal and child health: 2. maternal health findings. J Glob Health. 2017;7(1). doi:10.7189/jogh.07.010902

33. Gilson L, Hanson K, Sheikh K, Agyepong IA, Ssengooba F, Bennett S. Building the field of health policy and systems research: Social Science matters PLoS Med. 2011;8(8):e1001079. doi:10.1371/journal.p med.1001079 